\title{
Auxílio-Reclusão: um direito restrito
}

\author{
Juliana Medeiros Paiva
}

Universidade de Brasília (UnB)

\begin{abstract}
Auxílio-Reclusão: um direito restrito
Resumo: Esse artigo analisa o acesso ao auxílio-reclusão no Brasil, no período entre 2002 e 2012. O auxílio-reclusão é um benefício da previdência social que visa à proteção dos dependentes de pessoas presas que estejam em condição de segurada e que tenham baixa renda. Foi realizada análise longitudinal comparativa dos dados dos benefícios previdenciários pagos entre os anos de 2002 a 2012, bem como a análise dos dados sobre a população carcerária no mesmo período. Foi possível verificar o aumento no número de benefícios pagos e no volume de recursos destinados ao auxílio-reclusão, que cresceu mais que a média da maior parte dos benefícios previdenciários. Apesar disto, o auxílio-reclusão ainda é um benefício restritivo e com baixa cobertura, beneficiando 7\% da população carcerária do Brasil. Palavras-chave: Auxílio-reclusão. Previdência Social. Direito à informação. Pessoas presas.
\end{abstract}

\section{Incarceration Assistance: a restricted right}

Abstract: This article analyzes access to incarceration assistance in Brazil in the period from 2002- 2012. Incarceration assistance is a benefit of the social security system that is dedicated to the protection of dependents of people who are imprisoned who are eligible for social security benefits and have low income. A comparative longitudinal analysis of the data about social security benefits paid between the years 2002-2012 was conducted, and an analysis of data about the incarcerated population in the same period. The study found an increase in the number of benefits paid and in the volume of resources destined to incarceration assistance, which grew above the average of most of the social security benefits. Despite this, incarceration assistance is still a restricted benefit with low coverage, benefitting $7 \%$ of Brazil's incarcerated population.

Keywords: Incarceration Assistance. Social Security. Right to Information. Imprisoned people. 


\section{Introdução}

Os direitos das pessoas presas estão expressos no Código Civil Brasileiro de 1940, na Lei de Execuções Penais (LEP) de 1984 e na Constituição Federal de 1988. É direito de a pessoa presa manter todos os outros direitos não restritos pela condição do encarceramento. Os direitos estabelecidos, no Brasil, visam atender também às Regras de Tratamento Mínimo de Prisioneiros, documento elaborado pela Organização das Nações Unidas (ONU), em 1955, do qual o Brasil é signatário. Entre os direitos definidos pela LEP, encontra-se o direito à alimentação, ao trabalho, à saúde, à assistência (material, jurídica, educacional, social e religiosa) e à previdência social.

Instituído no Brasil ainda na década de 1960 e incorporado na Constituição Federal de 1988, o auxílioreclusão compõe o rol de direitos previdenciários e de direitos das pessoas presas. $\mathrm{O}$ auxílio é devido exclusivamente para as pessoas seguradas da previdência social que se encontram em algum regime de privação de liberdade - prisão provisória, regimes semiaberto e fechado, medida de segurança e medida socioeducativa de internação. De acordo com Dantas e Rodrigues (2009) e Demo (2009), o auxílio-reclusão é o único benefício, nesses moldes, conhecido no mundo.

O auxílio-reclusão é um benefício reconhecido como direito baseado na lógica do seguro social, devido àqueles que tenham contribuído anteriormente para a previdência social. A contribuição é feita de forma compulsória - por pessoas inseridas em trabalhos formais, ou de forma voluntária - por pessoas fora do mercado de trabalho, profissionais liberais ou trabalhadores informais. Como um seguro social, o auxílio-reclusão visa cobrir o risco de perda da renda devido à prisão da pessoa segurada e garantir proteção à sua família, sendo pago diretamente para os dependentes. O auxílio é pago em parcelas mensais durante o período em que a pessoa estiver reclusa, sendo necessária a comprovação da condição de reclusão a cada três meses.

De maneira geral, para a concessão do auxílio-reclusão a pessoa requerente precisa cumprir os seguintes critérios: a) a pessoa segurada que tiver sido presa não poderá estar recebendo salário do local na qual trabalhava, ou outros benefícios previdenciários; b) a prisão deverá ter ocorrido no prazo de manutenção da qualidade de segurada (doze meses desde a última contribuição); ${ }^{1}$ e c) o valor do último salário de contribuição deverá ser igual ou inferior ao valor fixado pela previdência, que em 2012 era de $R \$ 915,05^{2}$. Os dependentes da pessoa presa e segurada têm direito ao auxílio-reclusão independentemente da quantidade de contribuições realizadas antes da reclusão ${ }^{3}$.

Apesar da característica de seguro social, o auxílio-reclusão passou por um processo de mudança no perfil de concessão com as alterações trazidas pela Emenda Constitucional n. 20/1998. Ela instituiu que apenas as pessoas seguradas consideradas de baixa renda poderiam ter acesso ao benefício. Apesar de estabelecer o critério de seletividade restringindo o direito do recebimento do seguro apenas às pessoas presas consideradas pobres, a Emenda não estabeleceu parâmetros que definissem a categoria baixa renda, deixando a critério do poder executivo a definição posterior do que seria considerado o segurado pobre e o não pobre. Na EC n. 20/ 1998 , foi definido apenas o teto de $\mathrm{R} \$ 360,00$ para acesso ao benefício.

Até 2012, não havia sido editada ainda nenhuma Lei que estabelecesse o critério de baixa renda a ser utilizado pelo auxílio-reclusão e salário-família. ${ }^{4} \mathrm{O}$ que vem sendo realizado são atualizações anuais do valor estipulado pela EC n. 20/1998, corrigidos pelos mesmos índices de reajustes dos demais benefícios da previdência social por meio de portarias interministeriais do Ministério da Fazenda e Ministério da Previdência Social.

A restrição no acesso ao auxílio-reclusão foi desde a incorporação da EC n. 20/1998, alvo de diversas controvérsias jurídicas que resultaram em ações judiciais que buscavam declarar a inconstitucionalidade deste requisito, uma vez que o requisito de baixa renda é incompatível com os princípios norteadores da previdência social contributiva (RAUPP, 2009). A alteração trazida pela EC n. 20/1998 altera o critério de adesão e cobertura previdenciária, uma vez que o requisito para o direito é a contribuição anterior e não a renda auferida seja ela considerada baixa ou não. No caso do auxílio-reclusão, o critério para acesso é a privação de liberdade e a impossibilidade de manter a renda de seus dependentes devido à prisão, fato que independe da situação de renda anterior do segurado (RAUPP, 2009).

A EC n. 20/1998 também não definiu, de forma clara, se a baixa renda auferida se relacionava à renda da pessoa segurada ou à renda de seus dependentes. Esta indefinição sobre a renda passou a ser alvo, também, de diversas ações judiciais. Em 2009, o Supremo Tribunal Federal firmou entendimento de que o limite de renda estabelecido na EC n. 20/1998 para o auxílio-reclusão deveria ser respeitado. Além disso, definiu que a renda a ser considerada no ato da concessão do beneficio é a da pessoa segurada e não a dos dependentes, reduzindo as contestações judiciais (RAUPP, 2009).

A mudança no perfil de concessão do auxílio-reclusão é parte de um amplo processo pelo qual as políticas sociais e, em especial, a previdência social vêm passando. Essas alterações visam, sobretudo, o aumento da seletividade na prestação de benefícios e a perda de direitos sociais. A natureza do auxílio-reclusão foi modificada, fazendo com que se perdesse a característica de seguro social. O critério de seletividade incluído pela EC n. 20/ 
1998, aproxima o auxílio-reclusão de um benefício assistencial, que é devido àqueles extremamente pobres e que historicamente foi concebido como um benefício desprovido de seu caráter de direito.

Em meio a contínuas restrições, o auxílio-reclusão tem sido alvo de diversas especulações moralizantes que visam desqualificar o benefício e seus beneficiários. A concessão do auxílio-reclusão está, cada vez mais, envolta em polêmicas e preconceitos quanto a sua distribuição (PEREIRA; LOPES, 2012). Em pesquisa recente, Chies e Passos (2012) apontaram que um movimento iniciado em listas de e-mails e redes sociais na internet, a partir de 2009, retirou o auxílio-reclusão da quase invisibilidade e o levou ao amplo debate público denominado de "bolsa-bandido". Esse debate culminou na elaboração do Projeto de Emenda Constitucional (PEC) n. 30/2011, que visa restringir o acesso, a abrangência e a aplicação do benefício, apresentado pelo deputado federal Fernando Francischini (PSDB-PR). O projeto aguarda um posicionamento da Comissão de Constituição, Justiça e de Cidadania (CCJC). De acordo com a proposta, o auxílio-reclusão passaria a não ser devido a presos condenados por crimes hediondos.

Apesar dos avanços na definição dos direitos das pessoas presas, o Brasil não tem conseguido garantir a maior parte dos direitos estabelecidos pela LEP e Constituição Federal. De acordo com Wacquant (2011, p. 13), os estabelecimentos prisionais do Brasil "se parecem mais com campos de concentração para pobres, ou com empresas públicas de depósito industrial dos dejetos sociais, do que com instituições judiciárias servindo para alguma função penalógica". O Brasil apresenta um dos maiores números de pessoas em regime de privação de liberdade do mundo. De acordo com dados do Ministério da Justiça, a taxa de encarceramento no Brasil, em 2012, é de 245 presos para cada 100 mil habitantes. A taxa do Brasil só é menor do que a dos Estados Unidos, Rússia e China. Os estabelecimentos prisionais, no Brasil, apresentam, em sua maioria, superlotação, falta de funcionários, infraestrutura precária e uma série de outros fatores que restringem os direitos garantidos às pessoas presas, sendo projetadas, cada vez mais, como fábricas de exclusão social (WALMSLEY, 2010).

O Brasil é um dos três países com maior aumento da população carcerária na última década, ficando atrás apenas de países como o Camboja e El Salvador (WALMSLEY, 2010). Entre os anos de 2002 e 2012 a população carcerária teve um crescimento acumulado de $184 \%$, passando de cerca de 181 mil pessoas em 2002, para mais de 500 mil em 2012 (INFOPEN, 2012). Em meio a essa realidade de aumento da população carcerária, precarização do sistema penitenciário e restrição de direitos das pessoas presas, este artigo analisa o acesso ao auxílio-reclusão no Brasil no período entre 2002 e 2012. O objetivo é oferecer dados sobre este benefício ainda pouco estudado no Brasil e alvo de controvérsias jurídicas e morais. Dessa forma, a análise longitudinal dos dados da previdência social realizada neste estudo, busca analisar a cobertura, a abrangência e o financiamento do auxílio-reclusão sob o enfoque da seletividade do benefício.

\section{Procedimentos metodológicos}

Os dados analisados, neste estudo, foram coletados por meio de análise documental nos relatórios do boletim estatístico da previdência social dos anos de 2002 a 2012, bem como os dados sobre a população carcerária no período, disponíveis no Sistema de Informações Penitenciárias (Infopen). Os dados disponíveis nos relatórios do boletim estatístico previdência social foram agregados, por ano e por tipo de benefício, nas seguintes categoriais: a) Auxílio-reclusão; b) Benefícios de aposentadoria; c) Pensão por morte; d) Auxílios (exceto o auxílio-reclusão); e e) Benefícios assistenciais. Foram coletados dados sobre o número de benefícios de auxílio-reclusão pagos em cada estado e o montante de recursos destinados a cada ano. Os dados do auxílio-reclusão foram desagregados dos demais auxílios.

Os dados foram coletados em um formulário previamente elaborado e permitiram identificar a cobertura da população carcerária pelo auxílio-reclusão em diferentes estados da federação, além do aumento no número de benefícios pagos e no montante de recursos destinados. Foram coletados dados referentes ao montante de recursos destinados aos demais benefícios, agregados por ano, bem como o valor médio dos benefícios pagos em 2012, tendo como finalidade permitir a comparação entre o auxílio-reclusão e demais benefícios. Os valores monetários analisados foram atualizados para valores correntes por meio do uso do deflator baseado no Índice Geral de Preços do Mercado (IGP-M), com vistas a identificar o aumento ou decréscimo real dos recursos destinados aos benefícios.

Não há dados que relacionem o número de benefícios de auxílio-reclusão pagos e a cobertura da população carcerária com o benefício. As fontes de dados analisadas não se comunicam e a ausência de dados oficiais, sobre a realidade social das pessoas presas no Brasil, dificulta a análise do acesso a direitos sociais entre esse público. Dessa forma, os dados organizados, neste estudo, apresentam, pela primeira vez, a abordagem do acesso ao auxílio-reclusão tendo, como enfoque, a pessoa presa e não seus dependentes. 


\section{Auxílio-reclusão: um direito restrito}

Em 2012, a população carcerária do Brasil era de 549.577 pessoas presas. Desse total, 527.778 estavam presas nos regimes fechado, semiaberto ou provisório ou cumpriam medida de segurança, sendo 493.344 (93\%) homens e 34.434 (7\%) mulheres (INFOPEN, 2012). No mesmo ano, foram pagos 37.899 benefícios de auxílio-reclusão, o que representa o atendimento de aproximadamente 7\% das pessoas presas no Brasil. Nos últimos dez anos, a cobertura variou entre 3\% a 7\%, conforme demonstra os dados na tabela 1.

Tabela 1 - Cobertura da população carcerária com o auxílio-reclusão (2002-2012)

\begin{tabular}{|c|c|c|c|}
\hline Ano & Total de pessoas presas* & Total de benefícios emitidos ** & Percentual de atendimento \\
\hline 2002 & 232.910 & 9.119 & $3,9 \%$ \\
\hline 2003 & 308.304 & 11.569 & $3,7 \%$ \\
\hline 2004 & 336.358 & 12.251 & $3,6 \%$ \\
\hline 2005 & 353.529 & 14.164 & $4,0 \%$ \\
\hline 2006 & 382.925 & 16.105 & $4,2 \%$ \\
\hline 2007 & 403.443 & 18.949 & $4,7 \%$ \\
\hline 2008 & 430.887 & 22.377 & $5,1 \%$ \\
\hline 2009 & 454.168 & 26.645 & $5,8 \%$ \\
\hline 2010 & 477.505 & 29.467 & $6,1 \%$ \\
\hline 2011 & 495.949 & 33.245 & $6,7 \%$ \\
\hline
\end{tabular}

* Total de presos nos regimes provisório e semiaberto, fechado e em medida de segurança (posição em dezembro de cada ano).

** Benefícios efetivamente pagos (posição em dezembro de cada ano).

Fonte: Dataprev (SUB, Síntese) 2012 e Infopen 2002-2012. Elaboração da autora.

Embora o direito ao auxílio-reclusão seja procedente de uma pessoa segurada da previdência social que esteja presa, não há dados oficiais sobre esse público. Os dados sobre distribuição dos benefícios previdenciários identificam o sexo do dependente legal que recebe diretamente o auxílio-reclusão. Entre os dados estatísticos da previdência social, os únicos benefícios cujas informações apresentadas se referem aos dependentes e não aos segurados são o auxílio-reclusão e a pensão por morte. É compreensível a necessidade de identificar e fornecer dados sobre as pessoas que, de fato, recebem os benefícios previdenciários. Porém, a ausência de informação sobre a pessoa segurada impossibilita a realização de análises quanto ao alcance diferenciado de um ou outro benefício por perfis de escolaridade, renda, gênero e inserção laboral.

Os dados disponíveis impossibilitam verificar, por exemplo, quantos benefícios são gerados a partir de um homem ou de uma mulher presa. Devido à inexistência de dados que identifiquem o sexo das pessoas seguradas, a análise, a respeito da disponibilização do auxílio-reclusão nos últimos dez anos, não é capaz de identificar desigualdades de gênero no acesso e distribuição do benefício. Entre os dados da população carcerária, disponibilizados pelo Infopen, não há qualquer menção à cobertura desse benefício ou de outros benefícios assistenciais ou previdenciários. Também não existem dados sobre a situação anterior de trabalho das pessoas presas que possibilitem uma aproximação do debate sobre cobertura previdenciária no sistema prisional.

Ao que parece, um silêncio dos dados oficiais, a inexistência de informações sobre a população carcerária reflete os estigmas pelas quais estão submetidas as pessoas presas, que as identificam como destituídas de direitos. De acordo com Goffman (1988), o estigma é um tipo de percepção sobre os atributos individuais considerados fora do padrão ou da norma por valores pré-estabelecidos. Para o autor, o estigmatizado pode ser do tipo desacreditado, ou seja, aquele cujo estigma já é evidente de antemão, e o do tipo desacreditável, aquele cujo estigma pode passar a existir ou ser percebido. Os desacreditados, em geral, são os deficientes, os presos, os loucos, os desempregados, os negros ou, simplesmente, o estranho. 
A discriminação das pessoas estigmatizadas se baseia em uma lógica de inferioridade, capaz de restringir possibilidades de reconhecimento de direitos, de humanidade e necessidade de manutenção dessa vida considerada de menor valor que as vidas não estigmatizadas. De acordo com Butler (2010), existem vidas que não são reconhecidas nem apreendidas como vidas, o que se dá por uma distribuição diferencial do reconhecimento da precariedade humana e da necessidade de preservá-la. Porém, uma vida precisa antes ser inteligível como vida para que sua precariedade seja reconhecida.

\section{Ao que parece, um silêncio dos dados oficiais, a inexistência de informações sobre a população carcerária reflete os estigmas pelas quais estão submetidas as pessoas presas, que as identificam como destituídas de direitos.}

Os marcos pelos quais se dá o reconhecimento ou a apreensão de alguns tipos de vida se constitui de acordo com normas ou padrões socialmente estabelecidos e mantidos. São esses marcos que definem que vidas serão reconhecidas. Se a vida não é reconhecida, bem como sua precariedade e a necessidade de prover meios de mantê-la, seus direitos também não podem ser reconhecidos. Para ter acesso aos direitos qualificados como humanos, é necessário, antes, reconhecer a humanidade do sujeito que requer esses direitos. As prisões são estabelecimentos para onde são enviados seres considerados inimigos, abjetos, marcados pelo estigma do crime: os sem direito a ter direitos.

Para Foucault (2010), a permanência e ampliação da prisão se deu devido ao fato de exercer funções importantes na manutenção das relações de poder, por meio da gestão das ilegalidades da classe subalterna. Ao mesmo tempo, desempenha uma das engrenagens da economia dos exemplos necessária ao poder disciplinar. A prisão consegue, junto com as demais tecnologias disciplinares, dar tanto a docilidade quanto a utilidade dos corpos, visando ao adestramento dos indivíduos por meio do controle dos espaços, das atividades e do uso do tempo e principalmente por meio da economia do medo.

Segundo Garland (1999), as práticas penais se relacionam não somente ao crime e ao castigo, mas também à sociedade como um todo por meio dos efeitos de sua ação social, que organizam a estrutura do que é considerado bom ou ruim, normal ou desviante. As prisões foram tão amplamente difundidas que levam a um sentimento contemporâneo de inevitabilidade, além de necessárias para a regulação das infrações. A punição, de acordo com o autor, tem efeitos mais amplos do que o controle dos indivíduos. A prisão tem se tornado, cada vez mais, o lócus de geração e ampliação das desigualdades econômicas e sociais.

\section{Cobertura do auxílio-reclusão nos estados brasileiros}

Analisando a distribuição dos benefícios, entre os estados, é possível verificar que não existe uma relação entre o número total de presos do estado e a cobertura do benefício, o que sugere que outros fatores podem estar envolvidos no processo de concessão, tais como atendimento dos requisitos legais - estar em condição de segurado, dentro do limite de renda - além de acesso e disponibilidade de informação. A solicitação do auxílioreclusão é feita pelos dependentes diretamente aos postos de atendimento da previdência social, não havendo nenhum critério de distribuição geográfica prioritária do benefício. A cobertura do auxílio-reclusão, nas diferentes regiões brasileiras, variou, em 2012 , entre $0,8 \%$ e $14 \%$ (tabela 2).

De acordo com os dados analisados, a cobertura do benefício é menor nos estados da Região Norte, sendo que, no Amazonas, apenas $0,8 \%$ do total de presos recebia o auxílio-reclusão. Os estados da Região Sul tinham maiores taxas de cobertura do auxílio-reclusão (10\% a 14\%). Alguns indicadores complementares podem indicar possíveis causas da maior cobertura nesses estados. De acordo com dados da Pesquisa Nacional de Amostra de Domicílios - PNAD/IBGE, em 2011, a Região Sul tinha a menor taxa de desocupação do Brasil: $4,4 \%$ da população economicamente ativa. Na Região Norte, essa taxa era de $6,9 \%$. A Região Sul tinha, em 2011, a menor taxa de trabalhadores ocupados sem carteira assinada: $15,3 \%$. Na Região Norte essa taxa era de $24,1 \%$. Como uma das condições para o recebimento do auxílio-reclusão é a contribuição à previdência social, uma maior taxa de trabalhadores sem carteira assinada pode repercutir no acesso a esse benefício.

A Região Sul tinha também a maior proporção de pessoas ocupadas que contribuíam para a previdência. Enquanto a média nacional era de 58,2\%, na Região Sul, 67,2\% das pessoas ocupadas contribuía para a previdência e, na Região Norte, apenas 40,1\% (IBGE, 2011). Por meio da análise dos dados desagregados dos 
estados com menor e maior cobertura do auxílio-reclusão - Amazonas e Santa Catarina - é possível observar diferenças, ainda maiores, nos indicadores levantados pelo IBGE. No estado do Amazonas, a taxa de desocupação, em 2011, era de 7,9\%, enquanto Santa Catarina tinha a menor taxa do Brasil, com 3,5\%. Santa Catarina tinha, também, a maior proporção de contribuintes da previdência no Brasil: 75,6\%. No estado do Amazonas, essa proporção era de 42,3\% (IBGE, 2011).

Tabela 2 - Distribuição federativa - auxílio-reclusão (2012)

\begin{tabular}{|c|c|c|c|}
\hline Unidades da Federação & $\begin{array}{c}\text { Quantidade de benefícios } \\
\text { emitidos* }\end{array}$ & Total de pessoas presas** & $\begin{array}{l}\text { Percentual de } \\
\text { atendimento }\end{array}$ \\
\hline BRASIL & 37.899 & 527.778 & $7,2 \%$ \\
\hline Acre & 304 & 3.812 & $8,0 \%$ \\
\hline Alagoas & 168 & 3.798 & $4,4 \%$ \\
\hline Amapá & 37 & 1.821 & $2,0 \%$ \\
\hline Amazonas & 57 & 6.831 & $0,8 \%$ \\
\hline Bahia & 592 & 14.930 & $4,0 \%$ \\
\hline Ceará & 838 & 15.234 & $5,5 \%$ \\
\hline Distrito Federal & 748 & 11.452 & $6,5 \%$ \\
\hline Espírito Santo & 1.646 & 14.671 & $11,2 \%$ \\
\hline Goiás & 508 & 11.967 & $4,2 \%$ \\
\hline Maranhão & 105 & 5.232 & $2,0 \%$ \\
\hline Mato Grosso & 543 & 11.202 & $4,8 \%$ \\
\hline Mato Grosso do Sul & 761 & 11.390 & $6,7 \%$ \\
\hline Minas Gerais & 4.765 & 51.007 & $9,3 \%$ \\
\hline Pará & 163 & 12.496 & $1,3 \%$ \\
\hline Paraíba & 515 & 8.671 & $6,0 \%$ \\
\hline Paraná & 2.813 & 27.718 & $10,0 \%$ \\
\hline Pernambuco & 2.233 & 25.475 & $8,8 \%$ \\
\hline Piauí & 126 & 3.197 & $4,0 \%$ \\
\hline Rio de Janeiro & 1.706 & 33.192 & $5,1 \%$ \\
\hline Rio Grande do Norte & 524 & 6.169 & $8,5 \%$ \\
\hline Rio Grande do Sul & 2.959 & 28.487 & $10,4 \%$ \\
\hline Rondônia & 508 & 7.458 & $6,9 \%$ \\
\hline Roraima & 94 & 1.567 & $6,0 \%$ \\
\hline Santa Catarina & 2.114 & 15.153 & $14,0 \%$ \\
\hline São Paulo & 11.820 & 190.818 & $6,2 \%$ \\
\hline Sergipe & 261 & 3.756 & $7,0 \%$ \\
\hline Tocantins & 105 & 2.466 & $4,3 \%$ \\
\hline
\end{tabular}

* Total de presos nos regimes provisório e semiaberto, fechado e em medida de segurança (posição em dezembro de cada ano).

** Benefícios efetivamente pagos (posição em dezembro de cada ano).

Fonte: Dataprev (SUB, Síntese) 2012 e Infopen 2002-2012. Elaboração da autora. 
O nível educacional parece contribuir na obtenção do benefício, uma vez que a maior escolaridade tende a possibilitar a inserção em trabalhos mais bem qualificados e formais, além de facilitar o acesso a informações. Apesar da ausência de dados que possibilitem elencar fatores de inclusão e exclusão no benefício, foi possível verificar que, nos estados com maior cobertura do benefício, o perfil educacional dos presos era melhor que nos estados com menor cobertura. Nos estados com maior cobertura, o percentual de pessoas presas com escolaridade igual ou superior ao ensino médio incompleto variou entre $20 \%$ a $30 \%$. Em contrapartida, nos estados com menor cobertura, esse percentual variou entre 10\% a 17\% (INFOPEN, 2012).

Os indicadores levantados pelo IBGE reforçam a posição diferenciada das regiões brasileiras quanto ao número médio de anos de estudo da população brasileira. Enquanto a média nacional, em 2011, era de 7,3 anos de estudos, nos estados da Região Norte, a média era de 6,6 anos e, na Região Sul, de 7,7 anos (IBGE, 2011). De acordo com os dados nacionais da população carcerária, $70 \%$ tinham apenas o ensino fundamental incompleto quando foram presos e, em 2012, uma em cada duas pessoas presas tinham entre 18 e 29 anos. Ou seja, a maior parte da população carcerária é jovem, com baixa escolaridade e, provavelmente, não tenha ingressado em um trabalho formal antes da reclusão. Não há informações sobre a situação laboral dos indivíduos antes da prisão, tampouco sobre a renda média auferida com atividades profissionais anteriores, que possibilitem identificar a proporção de pessoas presas, cujas famílias poderiam ter acesso ao auxílio-reclusão e não o tem, ou se o atendimento verificado, nos últimos dez anos, é apenas um retrato do perfil da população carcerária no Brasil: o jovem desfiliado.

Para Castel (1998, p. 536), os desfiliados são caracterizados pela "ausência de inscrição do sujeito em estruturas portadoras de sentido". O processo de reestruturação produtiva advindo das transformações do sistema capitalista tem gerado um processo de precarização e vulnerabilidade social que tem formando uma nova classe de indivíduos: os desfiliados. O sistema capitalista, em especial o movimento de desregulamentação mais recente, teve como reflexo a desestabilização de uma fração importante do mercado de trabalho, incluindo a impossibilidade permanente de acesso ao trabalho e aos direitos advindos dele, e produz o indivíduo excluído por um duplo desligamento: do mercado de trabalho e da inserção relacional.

De acordo com os dados do IBGE, em 2011, cerca de 3\% da população economicamente ativa da Região Norte nunca ingressou no mercado de trabalho (formal ou informal). Na Região Sul, 1,3\% da população economicamente ativa nunca trabalhou. Em 2011, em todo Brasil, dois milhões e duzentos e oitenta mil pessoas, em idade economicamente ativa, nunca trabalhou. A maior parte da população que já trabalhou e se encontrava desocupada, em 2011, era composta por jovens entre 18 a 24 anos (IBGE, 2011). De acordo com Castel (1997), as pessoas marcadas pela desfiliação permanente têm um estatuto diferente dos pobres assistidos por direitos sociais. Essas pessoas são denominadas pelo autor como os sem-estatuto. São os sem-domicílio, sem família e principalmente o conjunto daqueles que serão colocados em espaços separados e em instituições totais, como a prisão.

Para Wacquant (2011), as prisões são, atualmente, muito mais um instrumento de administração da pobreza que simplesmente um aparato de castigo às infrações. A política de criminalização da pobreza passa a ser uma das respostas à falta de oportunidades de filiação via trabalho e possibilita a imposição de trabalhos precarizados à população. Em meio ao aumento do sistema penal, por meio do estabelecimento de novas leis, tipificação de novos crimes e estabelecimento de penas cada vez maiores, a prisão passa a ser o lugar cada vez mais destinado às infrações relacionadas ao uso de drogas e aos pobres desfiliados.

\section{Financiamento do auxílio-reclusão}

O orçamento da previdência social é composto, em maior parte, por contribuições dos empregadores e trabalhadores para a seguridade social. Essa concentração dos recursos, em contribuições dos empregadores e trabalhadores, denota um caráter regressivo das fontes de financiamento, uma vez que os encargos sociais dos empregadores são repassados aos preços dos produtos e serviços. Os encargos podem chegar a consumir $48 \%$ da renda das pessoas que vivem com até dois salários mínimos (BOSCHETTI; SALVADOR, 2006).

Os tributos regressivos, normalmente indiretos, penalizam os contribuintes mais pobres, uma vez que incidem sobre o consumo de bens e serviços prestados, em especial os alimentos, resultando em uma carga tributária proporcionalmente maior para os que recebem menos (MEDEIROS; BRITTO; SOARES, 2007). Os tributos progressivos, normalmente impostos diretos, incidem sobre a renda e o patrimônio e aumentam conforme cresce a renda do contribuinte.

Em 2012, de acordo com dados da Dataprev, o montante de recursos destinados ao pagamento de benefícios da previdência social somava mais de R $\$ 348$ bilhões, sendo a maior parte destinada aos benefícios da previdência social básica ${ }^{5}$. No mesmo ano, foram pagos cerca de 30 milhões de benefícios 
por mês, sendo que, destes, $66 \%$ eram aposentadorias, incluindo-as por tempo de contribuição, por idade e por invalidez; $28 \%$ eram pensões por morte; e 5,4\% eram auxílios, incluindo o auxílio-reclusão. O auxílio-reclusão representou $0,1 \%$ do total do valor gasto com o pagamento dos benefícios previdenciários, e 1,7\% do total dos auxílios. Em dezembro de 2012, os benefícios pagos de auxílio-reclusão totalizaram pouco mais de $\mathrm{R} \$ 25$ milhões. ${ }^{6} \mathrm{O}$ valor médio mensal pago pela previdência também difere entre os benefícios. Em dezembro de 2012, o valor médio pago para benefícios de aposentadoria foi de $\mathrm{R} \$ 840,00$; os de pensão por morte, $\mathrm{R} \$ 753,00$; os auxílios, $\mathrm{R}$ \$ 871,00; e os demais benefícios, cerca de $\mathrm{R} \$ 700,00$. Já para o auxílio-reclusão, o valor médio dos benefícios emitidos em dezembro de 2012 foi de $\mathrm{R} \$ 680$, inferior à maioria dos demais benefícios.

No período entre 2002 e 2012, houve um aumento de 416\% no número de benefícios de auxílio-reclusão emitidos. No mesmo período, a população carcerária brasileira aumentou 235\%. Também foi possível observar uma tendência de crescimento no volume de recursos disponíveis, apesar de ter havido uma redução dos recursos per capita. Quando foi estipulado o teto para o critério de baixa renda do segurado, o valor do limite do último salário de contribuição, bem como o valor máximo do auxílio-reclusão, era de $\mathrm{R} \$ 360,00$, o que correspondia a 2,7 salários mínimos. Em 2012, o valor tanto do teto quanto do benefício não era superior a $\mathrm{R} \$$ 915,05, o que correspondia a 1,4 salários mínimos.

Embora o valor do benefício não seja vinculado ao salário mínimo e sim ao chamado salário de benefício, calculado com base no valor dos salários de contribuição, a partir de 2004, os benefícios passaram a ser reajustados na mesma data de reajuste do salário mínimo (HORVATH, 2005). Ao não estabelecer um paralelo entre o salário mínimo e o conceito de baixa renda, o acesso ao auxílio-reclusão tende a ficar continuamente mais restritivo, uma vez que os reajustes no salário mínimo têm sido superiores aos índices de reajuste dos salários de benefício da previdência social.

Tabela 3 - Crescimento dos valores acumulados dos benefícios de auxílio-reclusão $\mathrm{X}$ demais benefícios previdenciários

\begin{tabular}{|c|c|c|c|}
\hline Benefício & $\begin{array}{l}\text { Valores do total de benefícios } \\
\text { pagos em 2002* }\end{array}$ & $\begin{array}{l}\text { Valores do total de benefícios } \\
\text { pagos em } 2012 *\end{array}$ & Percentual de aumento \\
\hline Auxílio-reclusão & $\mathrm{R} \$ 7.079 .828,80$ & $\mathrm{R} \$ 279.529 .351,96$ & $39,5 \%$ \\
\hline Aposentadorias & $\mathrm{R} \$ 10.231 .517 .497,98$ & $\mathrm{R} \$ 178.776 .000 .442,24$ & $17,5 \%$ \\
\hline Pensão por morte & $\mathrm{R} \$ 3.656 .365 .644,32$ & $\mathrm{R} \$ 65.400 .192 .555,96$ & $17,9 \%$ \\
\hline $\begin{array}{l}\text { Auxílios (exceto } \\
\text { reclusão) }\end{array}$ & $\mathrm{R} \$ 833.981 .613,90$ & $\mathrm{R} \$ 14.816 .648 .753,93$ & $17,8 \%$ \\
\hline $\begin{array}{l}\text { Benefícios } \\
\text { assistenciais }\end{array}$ & $\mathrm{R} \$ 1.022 .418 .313,76$ & $\mathrm{R} \$ 26.900 .549 .439,03$ & $26,3 \%$ \\
\hline $\begin{array}{l}\text { Todos os Benefícios } \\
\text { (previdenciários; } \\
\text { acidentários; e } \\
\text { assistenciais) }\end{array}$ & $\mathrm{R} \$ 15.353 .422 .256,22$ & $\mathrm{R} \$ 267.834 .896 .928,03$ & $17,4 \%$ \\
\hline
\end{tabular}

* Valores atualizados com uso do deflator IGP-M. Benefícios efetivamente pagos (posição em dezembro de cada ano). Fonte: Dataprev (SUB, Síntese) 2002-2012. Elaboração da autora.

Entre 2002 e 2012, o valor acumulado dos benefícios de auxílio-reclusão teve o maior aumento percentual entre os benefícios previdenciários: $40 \%$. No mesmo período, o valor acumulado dos benefícios de aposentadoria teve um aumento de $17 \%$, o de pensão por morte teve um aumento de $18 \%$ e os demais auxílios, excetuando o auxílio-reclusão, tiveram aumento de $18 \%$. O auxílio-reclusão registrou crescimento superior também aos benefícios assistenciais, que, no período, tiveram aumento no valor acumulado de $26 \%$. O crescimento maior do benefício, comparativamente aos demais, demonstra uma dupla e perversa realidade. Se, de um lado, o crescimento do benefício evidencia o acesso a direitos sociais, por outro, reflete conjuntamente o crescimento da população carcerária, em uma realidade de restrição desses mesmos direitos. 


\section{Considerações finais}

A análise realizada neste estudo revela que, apesar do crescimento na taxa de cobertura pelo auxílioreclusão nos últimos dez anos, o acesso ao benefício é seletivo e restritivo. Em 2012, apenas 7\% da população carcerária brasileira tinha acesso ao auxílio-reclusão. A cobertura praticamente dobrou desde 2002, onde apenas 3,9\% das pessoas presas tinham acesso. De 2002 a 2012, a população carcerária brasileira aumentou $235 \%$ e, no mesmo período, o número de benefícios de auxílio-reclusão aumentou $416 \%$. O volume de recursos destinados ao pagamento dos benefícios de auxílio-reclusão teve um aumento superior a todos os demais benefícios da previdência. Apesar disso, esse volume não chega a representar mais do que $0,1 \%$ do total gasto pela previdência social.

Sob a alegação de reduzir o déficit da previdência social, a natureza do auxílio-reclusão foi modificada, fazendo com que se perdesse a característica de seguro social. Porém, é importante ressaltar que, embora a economia obtida por meio da seletividade de renda do auxílio-reclusão seja irrisória, uma vez que a participação do benefício é uma das menores no orçamento da previdência, a EC n. 20/1998 trouxe modificações expressivas nas regras de aposentadorias e pensões. Essas modificações refletiram na redução de direitos previamente conquistados por meio da ação de uma lógica restritiva. $\mathrm{O}$ auxílio-reclusão nada mais é que um seguro, ou seja, somente tem direito a requerer e receber quem é considerado segurado da previdência, quem contribuiu ou contribui para todo o sistema previdenciário brasileiro. Negar ou restringir o acesso a esse direito é desmobilizar todos os critérios previdenciários acordados na Constituição Federal.

Atrelado à restrição imposta ao benefício pela EC n. 20/1998, a própria característica do benefício impõe dificuldades de acesso à população carcerária. Para ter direito ao auxílio-reclusão, é preciso uma combinação de fatores quase improvável dentro do universo prisional: ter inserção anterior em um trabalho formal, ter baixa renda e estar encarcerado. A concessão do benefício envolve ainda a disponibilidade de informações sobre o direito e as formas de acesso, bem como um longo trâmite administrativo que parte da população elegível a recebê-lo desconhece.

A ausência de dados sobre a população carcerária, tais como situação laboral anterior ou mesmo dados previdenciários sobre o universo das pessoas presas que recebem o auxílio-reclusão, dificulta a análise e propositura de medidas que ampliem o acesso a esse benefício. A garantia dos direitos das pessoas presas é permanentemente posta à prova, seja por comoções populares contra pessoas que cometem infrações, seja por contínuas violações desses direitos em diferentes instituições penais. Garantir o acesso aos direitos de pessoas presas passa necessariamente pela ampliação do acesso a informações sobre direitos e benefícios destinados a essa população. A garantia de renda aos dependentes da pessoa presa, durante o período de reclusão, proporcionada pelo benefício pode, em muitos casos, ser a única disponibilidade de uma renda fixa mensal, podendo garantir ainda a manutenção dos vínculos familiares, o retorno da pessoa presa ao convívio de seus dependentes e reais possibilidades do rompimento do círculo vicioso da exclusão.

\section{Referências}

BOSCHETTI, I.; SALVADOR, E. Orçamento da seguridade social e política econômica: perversa alquimia. Serviço Social \& Sociedade, São Paulo: Cortez, n. 87, p. 25-57, 2006.

BRASIL. Constituição da República Federativa do Brasil. Promulgada em 5 de outubro de 1988. Brasília, 1988. . Lei n. 7.210, de 11 de julho de 1984. Institui a Lei de Execução Penal. Diário Oficial da União, 13 jul. 1984.

. Lei n. 8.213, de 24 de julho de 1991. Dispõe sobre os Planos de Benefícios da Previdência Social e dá outras providências. Diário Oficial da União, 25 jul. 1991.

. Câmara dos Deputados. Projeto de Emenda a Constituição n. 30/2011. Brasília, 2011. Disponível em: <http://www.camara.gov.br/ proposicoesWeb/prop_mostrarintegra;jsessionid=7F280A5975B5E193E756ECCB38457C28.node2? codteor=873634\&filename $=$ Tramitacao-PEC+30/2011>. Acesso em: 5 jan. 2013.

BUTLER, J. Marcos de guerra. Las vidas lloradas. Traducción de Bernardo Moreno Carrillo. Barcelona: Paidós Ibérica, 2010.

CASTEL. R. A dinâmica dos processos de marginalização: da vulnerabilidade à desfiliação. Cadernos CRH, n. 26-27, 1997. . As metamorfoses da questão social. Tradução de Iraci D. Poleti. Petrópolis: Vozes, 1998.

CHIES, L. A. B.; PASSOS, R. A. Auxílio-reclusão: a bizarra transmutação de um direito social e sua colonização perversa por um populismo punitivo. Textos \& Contextos, Porto Alegre, v. 11, n. 2, p. 273-291, ago./dez. 2012.

DANTAS, E. de A.; RODRIGUES, E. B. de O. Auxílio-reclusão: uma abordagem conceitual. Informe de Previdência Social, v. 21, n. 6, p. 1-13, jun. 2009.

DATAPREV. Empresa de Tecnologia e Informações da Previdência Social. Boletim Estatístico da Previdência Social (2002-2012). Disponível em: <http://www.mps.gov.br/conteudoDinamico.php?id=423>. Acesso em: 16 dez. 2012. 
DEMO, R. L. L. O auxílio-reclusão na previdência social brasileira e estrangeira. Revista do Tribunal Regional Federal da $1^{a}$ Região, v. 21, n. 6/7, jun./jul. 2009.

FOUCAULT, M. Vigiar e punir: nascimento da prisão. Tradução de Raquel Ramalhete. Rio de Janeiro: Vozes, 2010.

GARLAND, D. As contradições da "sociedade punitiva": o caso britânico. Revista de Sociologia e Política, Curitiba, n. 13, p. 59-80, nov. 1999.

GOFFMAN, E. Estigma: notas sobre a manipulação da identidade deteriorada. Tradução de Mathias Lambert. Rio de Janeiro: LTC, 1988. HORVATH, M. V. F. Auxílio-reclusão. São Paulo: Quartier Latin, 2005.

IBGE-Instituto Brasileiro de Geografia e Estatística. Pesquisa Nacional de Amostra de Domicílios - 2011. PNAD/IBGE, 2011. Disponível em: <http://www.ibge.gov.br/home/estatistica/populacao/trabalhoerendimento/pnad2011/default.shtm>. Acesso em: 20 mar. 2013.

INFOPEN-Sistema Integrado de Informações Penitenciárias. Dados consolidados e dos estados (2002-2012). 2012. Disponível em: <www.infopen.gov.br>. Acesso em: 16 dez. 2012.

MEDEIROS, M.; BRITTO, T.; SOARES, F. Transferência de renda no Brasil. Novos Estud. - Cebrap, São Paulo, n.79, p. 5-21, nov. 2007.

PEREIRA, S. C. de D.; LOPES, T. G. Maximização dos direitos fundamentais pelo benefício previdenciário do auxílio-reclusão. Revista SJRJ, Rio de Janeiro, v. 19, n. 35, p. 59-71, dez. 2012.

RAUPP, D. Auxílio-reclusão: inconstitucionalidade do requisito baixa renda. Revista CEJ, ano 13, n. 46, p. 62-70, jul./set. 2009.

WACQUANT, L. As prisões da miséria. Tradução de André Telles. Rio de Janeiro: Jorge Zahar, 2011.

WALMSLEY, R. World Prison Population List. International Centre for Prison Studies King's College London, School of Law. 2010. Disponível em: 〈http://www.idcr.org.uk/wp-content/uploads/2010/09/WPPL-9-22.pdf〉. Acesso em: 10 out. 2013.

\section{Notas}

1 Oinciso II do artigo 15 da Lei n. 8.213/1991 estabelece que o segurado obrigatório que deixar de exercer atividade remunerada ou estiver suspenso ou licenciado sem remuneração mantém-se segurado por até 12 (doze) meses após a cessação das contribuições. Caso tenha pagado mais de 120 contribuições, com ou sem interrupção, mas sem perder a qualidade de segurado, esse prazo poderá ser prorrogado para até 24 (vinte e quatro) meses. Se o segurado comprovar que está desempregado, esse prazo ou aquele de 12 (doze) meses pode ser prorrogado por mais 12 (doze) meses (BRASIL, 1991).

2 Os valores máximos do último salário de contribuição, bem como os valores dos benefícios são reajustados anualmente por meio de Portaria interministerial do Ministério da Fazenda e do Ministério da Previdência Social.

3 A maior parte dos benefícios previdenciários estabelece o número mínimo de contribuições para o seu acesso, ou seja, existe uma carência. ALei n. 8.213/1991, no artigo 26, inciso I, estabeleceu que, para o acesso aos benefícios - pensão por morte, auxílio-reclusão, salário-família e auxílioacidente-nãoé preciso carência. Essaé uma inovação, uma vez que, antes da dessa lei, eram necessárias 12 contribuições prévias (BRASIL, 1991).

4 Outro benefício restrito pelo critério de renda na EC n. 20/1998.

5 Os benefícios da Previdência Social Básica são divididos em: 1) Benefícios do Regime Geral da Previdência Social (BRGPS) e 2) Benefícios Assistenciais (BA). Os BRGPS se dividem em: a) previdenciários, o que inclui: i) aposentadorias (tempo de contribuição, idade, invalidez); ii) pensão por morte; iii) auxílios (doença, reclusão e acidente); iv) salário-maternidade; ev) outros (salário-família, abono de permanênciae vantagem de servidor); b) acidentários que inclui: i) aposentadoria por invalidez; ii) pensão por morte; iii) auxílio (doença, acidente e suplementar). Os BAs são divididos em: a) amparos assistenciais que inclui: i) deficiente; ii) idoso; b) pensão mensal vitalícia; c) renda mensal vitalícia que pode ser por: i) invalidez; e ii) idade.

6 Valores corrigidos pelo deflator IGP-DI.

Juliana Medeiros Paiva

Julianna.paiva@gmail.com

Doutoranda em Política Social pela Universidade de Brasília (UnB)

Pesquisadora do Instituto de Bioética, Direitos Humanos e Gênero (Anis)

Anis

Caixa Postal 8011

Sudoeste

Brasília - Distrito Federal - Brasil

CEP: 70673-970 